NASA Technical Memorandum 107077

\title{
A Numerical Study of the Effect of Wake Passing on Turbine Blade Film Cooling
}

James D. Heidmann

Lewis Research Center

Cleveland, Ohio

Prepared for the

31st Joint Propulsion Conference and Exhibit cosponsored by AIAA, ASME, SAE, and ASEE San Diego, California, July 10-12, 1995

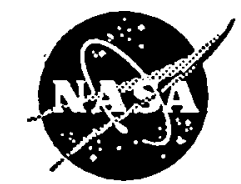

National Aeronautics and Space Administration

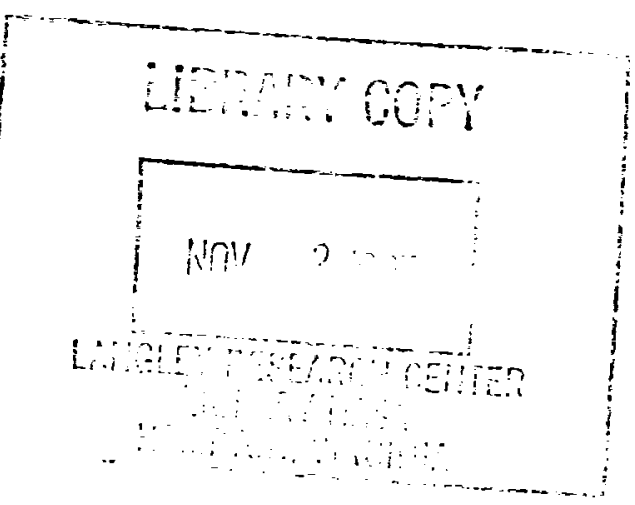




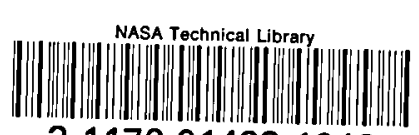

उ 1176014231949

\title{
A NUMERICAL STUDY OF THE EFFECT OF WAKE PASSING ON TURBINE BLADE FILM COOLING
}

\author{
James D. Heidmann* \\ National Aeronautics and Space Administration \\ Lewis Research Center \\ Cleveland, Ohio 44135 USA
}

\begin{abstract}
Time-accurate and steady three-dimensional viscous turbulent numerical simulations were performed to study the effect of upstream blade wake passing unsteadiness on the performance of film cooling on a downstream axial turbine blade. The simulations modeled the blade as spanwise periodic and of infinite span. Both acrodynamic and heat transfer quantities were explored. A showerhead film cooling arrangement typical of modem gas turbine engines was employed. Showerhead cooling was studied because of its anticipated strong sensitivity to upstream flow fluctuations. The wake was modeled as a region of zero axial velocity on the upstream computational boundary which translated with each itcration. This model is compatible with a planned companion experiment in which the wakes will be produced by a rotating row of cylindrical rods upstream of an annular turbine cascade. It was determined that a steady solution with appropriate upstream swirl and stagnation pressure predicted the span-average film effectiveness quite well. The major difference is a 2 to 3 percent overprediction of span-average film effectiveness by the steady simulation on the pressure surface and in the showerhead region. Local overpredictions of up to 8 percent were observed in the showerhead region These differences can be explained by the periodic relative lifting of the boundary layer and enhanced mixing in the unsteady simulations.
\end{abstract}

*Aerospace Engineer, Propulsion Systems Division

\section{INTRODUCTION}

Turbomachinery flow fields are inherently unsteady due to the relative motion of adjacent blade rows. The passing of wakes from the upstream blade row causes periodic fluctuations in both the magnitude and relative direction of the flow velocity in the downstream blade row. In addition, secondary flows are induced by turning of the radially non-uniform flow fields entering upstream blade rows. Sharma et al. [1] claim that this flow unsteadiness has an adverse effect on turbomachinery efficiency of several points relative to the steady time-mean flow. In turbines, this is likely due in large part to the effect of the flow unsteadiness on turbine blade boundary layer transition [2].

A useful figure of merit for aircraft turbine engines is the specific fuel consumption, or SFC. This is the rate of fuel consumption per unit thrust of the engine. For a given flight Mach number, the minimum ideal SFC is dependent on turbine inlet temperature. As turbine inlet temperature increases, minimum ideal SFC decrcases, so there is a continual incentive to increase the turbine inlet temperature. This incentive has given rise to turbine inlet temperatures several hundred degrees above current blade material operating temperatures. Due to thermal limitations of turbine materials, the turbine blades must often be cooled by passing cooler compressor air through the blades. When internal cooling alone is inadequate, film cooling must be employed in the first several blade rows [3]. In this case, the coolant air is discharged through small holes in the turbine surface to form a protective film between the turbine blade and the hot combustor discharge gas. These holes are usually concentrated on the pressure surface and leading edge region of the blades. To remain effective, the film coolant must remain near the surface and not separate into the free stream. However, mechanical constraints prohibit ejection at very small angles from the blade surface. Thus it is extremely important to know the trajectory of the film coolant under a variety of flow conditions. 
Until this time, most detailed research of the film coolant flow has considered the turbine free stream flow to be steady [4]. Studies of film cooled turbine stages have included unsteadiness [5], but have lacked sufficient detail to isolate the important physical phenomena associated with film coolant flow. To this end, this study aims to investigate the effect of flow unsteadiness on turbine film cooling in a more detailed and fundamental manner. Previous research has considered showerhead cooling on a flat body with a blunt leading edge. For example, Mick and Mayle [6] conducted steady showerhead film cooling experiments on a circular leading edge with a flat afterbody and found large gradients in the showerhead region for both film effectiveness and heat transfer coefficient. Detailed experimental results for showerhead film cooling with representative blade geometrics, particularly in the unsteady environment, are lacking in the literature.

Research is continuing throughout the industry to develop new turbine blade materials, both metallic and non-metallic, which are able to withstand higher temperatures. However, even if materials are developed in the future which safely withstand current turbine inlet temperatures, the incentive will remain to achieve even higher turbine inlet tempcratures through cooling of the new material. Thus it secms that turbine film cooling will remain a valid research concern well into the $21 \mathrm{st}$ century.

\section{PROBLEM DESCRIPTION}

In theory, the unsteady flow field in a turbine can be modeled using current threc-dimensional viscous unsteady flow codes. Such codes can even model film cooled blades through flow injection at selected grid points [5]. However, the computational time required for such a computation in sufficient detail for this problem would be enormous, making it impractical to perform a parametric study of the important variables. In addition, it is not guaranteed that an improved understanding of the flow physics would be obtained from such an effort. Therefore this problem is studied through a combination of physical and computational experiments. These experiments are flexible enough to allow application to an appropriate matrix of operating conditions and detailed enough to cnable accurate interpretation of the underlying flow physics. Through this effort, it is anticipated that improved physics-based unsteady film coolant flow models will be formulated and incorporated into the steady design codes.

The unsteady effects in turbines can generally be divided into two classes: two-dimensional cffects associated with wake and shock passing and potential interactions, and effects generated by three-dimensional secondary flows in upstream blade rows. These secondary flows include tip clearance vortices, passage vortices, horseshoc vortices, and the relative eddy. It is expected that the primary unsteady effect on film coolant flow in subsonic and moderately transonic turbines is due to wake passing, especially near midspan. Further, secondary flows are highly dependent on the turbine geometry, and are not easily generalized to a broad range of problems. Thus it seems proper to concentrate on the effect of wake passing on the film coolant flow. This can be accomplished using a rotating rod arrangement upstream of a turbine cascade [7]. Such an arrangement produces a periodic wake pattern which impinges on the turbine blades. The rods are sized to match the trailing edge diameter of an appropriate inlet guide vane for the test turbine. There is some debate as to the similarity of cylinder wakes to blade wakes [8]. However cylinder wakes have been shown [9] to accurately represent the relative velocity vector diagram and mean wake velocity profiles of an actual inlet guide vane.

The NASA Lewis Rotor-Wake Heat Transfer Rig (Figure 1) was chosen as an appropriate facility to investigate wake induced unsteadiness effects. The computation described in this report attempts to model the geometry and flow conditions to be studied in the future companion experiment. In this experiment, a rotating set of $0.32 \mathrm{~cm}$ diameter cylindrical rods are placed upstream of an annular turbine cascade consisting of 23 blades [10]. A maximum of 24 rods may bc used in the rotor. The rotor speed is adjustable up to 7000 $\mathrm{rpm}$. The cascade is representative of a lightly loaded turbine rotor. The blades have 67 degrees of tuming and one blade is film-cooled and instrumented. The instrumentation will consist of nickel thin film gauges capable of resolving both chordwise and spanwise variations in unsteady temperature. This information will be used to determine unsteady film effectiveness and heat transfer coefficient profiles on the blade surface for comparison with the computational results of this study.

The film cooling scheme consists of five staggered rows of showerhead film holes. The pitch-to-diameter ratio in both the spanwise and streamwise directions is 4.0. The holes are angled 30 degrees to the blade in the spanwise direction, and 90 degrees in the streamwise direction. Showerhead cooling was chosen because of the more pressing need for film cooling [5] and the larger temporal fluctuations in static pressure [11] in the leading edge region. 


\section{UNSTEADY COMPUTATION DESCRIPTION}

A three-dimensional viscous turbulent calculation was performed for the experimental geometry using the code RVC3D [12]. The code solves the thin-layer Navier-Stokes equations with an explicit finite-difference technique. The Baldwin-Lomax turbulence model was employed. The calculation modeled the flowfield as a linear cascade with spanwise periodicity based on a unit cell of the film hole pattem. Although the experiment is not precisely periodic due to the annular geometry and endwall effects, this simplification greatly reduces the number of grid points required to resolve the flow field. This is especially important for unsteady calculations. The blade-to-blade $\mathrm{C}$-grid consisted of 305 points tangential to the blade and 90 points normal to the blade (Figure 2). The large number of grid points in the blade-to-blade direction were required to adequately resolve the wake at the upstream boundary, particularly along the grid line from the upstream comers to the blade. The grid upstream boundary was located at the plane of the rotor. The passing wakes were modeled using a zero axial velocity boundary condition on a patch of the upstream boundary. This patch translated with each iteration based on a design rotor speed of $5800 \mathrm{rpm}$, and produced a 1:1 ratio of wakes to blades. The experimental ratio is $24: 23$. The non-wake portion of the upstream boundary was modeled by constant stagnation pressure and purcly axial flow. The entire upstream boundary used extrapolated static pressure.

The three-dimensional grid consisted of 20 grid points in the spanwise direction, and was produced by simply stacking the two-dimensional grid of Figure 2 in the spanwise direction, producing an orthogonal surface grid (Figure 3). The film holes were modeled using approximately 81 grid points per hole. Grid points were packed in the leading edge region to increase the number of grid points in the holes. The blade boundary conditions were modified in the following manner. At each surface grid point, the code determined from geometry whether the grid point was a hole point or a wall point. Wall points were given standard viscous adiabatic wall boundary conditions. Hole points were given inlet boundary conditions based on fully developed circular duct flow and extrapolated static pressure. A stagnation temperature and stagnation pressure of 0.65 and 1.03 times cascade upstream values, respectively, were assumed for the film coolant plenum. These values were chosen to produce density and blowing ratios similar to those found in actual engines. The flow angle at hole points was fixed at the gcometric angle of the holes themselves, which is a 30 degrec angle to the blade in the spanwise direction. This angle produces a 2:1 aspect ratio ellipse at the blade surface. Figure 3 shows the surface grid with all hole points removed. Because of the discontinuity between wall and hole, wall and hole boundary conditions were smoothly interpolated for points straddling the boundaries. It was determined that this method was preferred over attempting to distort the surface grid to conform to the elliptical holes. Such distortions were found to produce spatial spikes of increased entropy upon close inspection of earlier calculations.

The unsteady calculation was performed on the NASA Lewis Cray Y-MP supercomputer. Implicit residual smoothing was employed using a spatially-varying coefficient with a maximum value of 0.75 , allowing a maximum CFL number of about 7.7. The maximum time step was limited due to stability considerations by the grid spacing at the wall. For heat transfer calculations, a $y^{+}$of less that 1 is recommended at the first grid point away from the wall. However, such a spacing would have resulted in unacceptably large run times. Because of the adiabatic wall boundary condition and the resulting lack of temperature gradients at the wall, it was decided to relax $y^{+}$to the order of 5 at the first grid point. Approximately 2.5 hours of CPU time were required for a single wake passing period. 13 wake passings were required for the solution to converge. Residuals based on density were computed eight times per wake passing by comparing the current solution with the previous wake passing solution at the same phase. The solution was considered converged when the residuals had decreased by at least three orders of magnitude. The residuals were reduced another order of magnitude as a check, and there were no appreciable changes in the solution. The unsteady solution was then averaged with time over one wake passing to allow for meaningful comparison with steady solutions. This average was obtained by time-averaging pressure, temperature, and the three components of velocity at each grid point.

\section{STEADY COMPUTATION DESCRIPTION}

In order to isolate the time-average effect of the wake passing on the blade film effectiveness distribution, a companion steady solution was produced using an identical solution procedure to the unsteady case, except the wake boundary condition was removed. The time-averaged unsteady solution was used as the starting solution for this computation. The steady solution had no wake on the upstream boundary, so it was necessary to apply a stcady stagnation pressure and tangential velocity 
boundary condition. Since a tangentially varying boundary condition would be difficult to estimate for a steady solution a priori, tangentially constant stagnation pressure and tangential velocity were applied. In order to best model the unsteady solution with a steady solution, it is important to match the time-averaged flow rate of the coolant and the flow split of the coolant between the suction and pressure sides of the blade. If this is not done, any differences between the solutions may simply be due to a different amount of coolant flow on one or both surfaces of the blade. The coolant flow rate and flow split are determined by the local static pressure and stagnation line at the blade surface, which in turn can be controlled in the steady solution by changing the upstream stagnation pressure and the upstream swirl, respectively.

An initial attempt at a matching steady solution employed a zero inlet tangential velocity condition with an inlet stagnation pressure equal to the time- and circumferential-average inlet stagnation pressure from the unsteady solution. The stagnation pressure was computed to be about 0.99 times the unsteady solution non-wake stagnation pressure. This first steady solution was found to predict a greater coolant flow rate than the unsteady solution by several percent. In addition, a greater percentage of the coolant flowed to the suction side of the blade in the steady prediction. These differences indicated that a higher inlet stagnation pressure and a positive inlet swirl (in the wake direction) were necessary to match the time-average coolant flow properties from the unsteady solution. After several iterations, it was found that the desired stagnation line and hence coolant flow split could be produced by requiring a very small amount of swirl in the steady solution, about ten percent of the average inlet swirl in the unsteady solution. It was also determined that the correct showerhead region static pressure and hence film hole flow rate could be achieved by using a stagnation pressure about midway between the unsteady solution time-average and non-wake inlet stagnation pressures.

\section{RESULTS}

Figures 4 and 5 show the blade-to-blade entropy for two snapshots in time of the unsteady calculation. These plots are useful for determining the location of the wake with time. The wake can be seen as a region of increased entropy impinging on the leading edge of the blade. The dark region near the blade is the low entropy flow resulting from the film coolant. A slight thickening of the coolant flow layer can be seen on the pressure side of the blade in Figure 5 as the previous wake passes. This indicates that the wake has an effect on the coolant now on the pressure surface of the blade. Disturbance of the film on the suction side is not as apparent. These effects will be investigated in more detail in later figures which compare the steady and unsteady solutions.

Figure 6 is a contour plot of time-average adiabatic film effectiveness for the unsteady computation in the showerhead region. The film effectiveness is defined as:

$$
\eta=\left(T_{0, \text { in }}-T_{a w}\right) /\left(T_{o, i n}-T_{0, c}\right)
$$

where $T_{0, \text { in }}$ is the inlet stagnation temperature, $T_{\mathrm{aw}}$ is the adiabatic wall temperature, and $T_{o, c}$ is the coolant stagnation temperature. The blade contour is shown as an unwrapped flat surface. The computational domain (one unit cell of film hole patterm) is repeated 3 times in the spanwise direction. The spanwise direction of the coolant is upward in the figure. The five rows of film holes can be seen as black ellipses, with streaks of high film effectiveness extending downstream. The locations of these streaks change slightly with time, especially near the holes. Because of the higher free-stream acceleration on the suction side, the coolant flow is turned more quickly to the chordwise direction, while the pressure side coolant flow migrates more in the spanwise direction initially. The lowest film effectiveness (highest temperature) is seen in the region between the two suction side rows of holes, just upstream of the last suction side hole. A similar region exists just upstream of the last pressure side hole. These are regions that are not protected by the coolant, and are exposed directly to the frec-stream temperature. Their location is determined by the film hole pattern and the injection angle of the coolant. Since the holes are closely spaced in the spanwise direction, staggered, and angled sharply in the spanwise direction, the coolant from a given hole can be seen to align with that of those downstream. Thus for high angle, closedly spaced holes, an aligned or less structured staggered hole pattern may be more effective than this structured staggered hole pattern for reducing the maximum blade temperature.

The difference between the adiabatic film effectiveness for the time-average of the unsteady calculation and the final steady solution is shown on the unwrapped showerhead region in Figure 7 . It can be seen that the wake passing causes a decrease in film effectiveness over a large portion of the stagnation region, with a maximum decrease of 8 percent between the second and third row of holes. A smaller increase with a maximum value of 3 percent can be seen over an adjacent area. Differences in local film effectiveness can be deceiving, however, because at some locations the film eflectiveness distribution is similar between the two 
solutions and merely shifted spanwise, producing no net change in span-averaged film effectiveness.

Figure 8 is a plot of span-average film effectiveness versus surface distance for the time-average of the unsteady solution. As in the time-averaging process, pressure, temperature, and the three components of velocity were area-averaged in the spanwise direction. with all velocities being zero at the wall. In the showerhead region, only solid-wall grid points were included in the averaging process.

In Figure 9, the difference in span-averaged film effectiveness between the two steady solutions and the time-average unsteady solution are plotted directly. It can be seen that the modifications made to the final steady solution improve the film effectiveness prediction, and there are only small differences between the final steady and time-average unsteady film effectivenesses. The most notable differences are the reduction in film effectiveness over most of the pressure surface and the reduction in the showerhead region. There is also a reduction near the trailing edge on the suction surface, which is most likely due to a small unsteady separation bubble induced by the wake passing effect in the unsteady solution. The maximum differences are about 2 to 3 percent of the inlet stagnation tempcrature. Although small on a relative basis, the difference is significant, as it could translate to a $25^{\circ} \mathrm{C}$ difference in a high temperature turbine. Local variations as shown in Figure 7 are even greater, up to 8 percent.

Shown in Figure 10 are eight snapshots in time of the unsteady solution. These snapshots are equally-spaced in time over one wake passing period. The quantity plotted in Figure 10 is the difference between each instantaneous span-average film effectiveness and the time- and span-average unsteady film effectiveness. The large instantancous fluctuations in span-average film effectiveness of up to 15 percent are reflective of the location of the wake on the blade and its effect on the coolant flow. However the unsteady fluctuations largely cancel each other over time with respect to the steady solution except in the regions previously indicated. The maximum unsteady perturbation is in the showerhead region, as expected. It is interesting that at about 10 to 15 hole diameters on the suction side, the unsteady perturbation is very small. This location coincides with the approximate impingement point of the wake, as indicated by Figures 4 and 5.

Figure 11 highlights the bchavior of the film jets as they exit the blade. Stagnation tempcrature contours at the wall and on three spanwise grid planes normal to the surface for the time-average unsteady calculation are shown. The normal planes are on the near pressure surface of the blade, corresponding to surface distances of about $-5.5 ;-8.5$, and -11.5 hole diameters in Figures 8 and 9. The dark oval regions on the normal planes indicate lower stagnation temperature, and correspond to flow from the upstream film coolant holes. Also shown in Figure 11 are time-average particle traces from the film holes. As previously mentioned, the staggered hole arrangement causes flow from holes in adjacent rows to merge, resulting in the appearance of discrete jets at these locations rather than as the preferred smooth buffer layer. Since spanwise variations diminish in the streamwise direction as reflected by Figure 6, different scales are used for the three normal planes in Figure 11 to highlight the coolant jet location.

Because it was established that the coolant flow rate and flow split between pressure and suction sides for the unsteady solution were matched in the final steady solution, the small differences in span-average film effectiveness between the time-average unsteady and final steady cases is likely due to differences in stagnation temperature distribution normal to the blade surface. For example, although the flow rate and stagnation temperature of coolant on each surface is matched, the coolant may exhibit differences in its rate of diffusion into the free stream or separation characteristics. Normal span-average stagnation tcmperature distributions are plotted in Figure 12 for two locations of interest. The stagnation temperature is normalized by the inlet stagnation temperature. Referring to the final steady plot in Figure 9, the first is the sharp minimum near the stagnation point. The second is the broader minimum on the pressure side at a surface distance of about -25 hole diameters. At both locations, the unsteady span-average film effectiveness is slightly less than the steady prediction, meaning the unsteady span-average wall temperature exceeds the steady prediction, and the film effectiveness is lower. In Figure 12, it can be seen that although the unsteady wall temperature exceeds the steady wall temperature at both locations, the reverse is true farther away from the wall. This indicates that the coolant has penetrated into the free stream to a greater extent in the unsteady case, and that the differences in film effectiveness exhibited in Figure 9 are indeed due to unsteady effects and not merely caused by changes in coolant flow rate or flow split.

To identify the unsteady mechanism causing the reductions in film effectiveness on the pressure surface, it is helpful to examine Figures 4 and 5. Although the time-average location of the wake is primarily near the 
suction side of the blade, this is not a good indicator of impact on the film coolant. This is because the wake wraps around the suction side, as can be seen in Figure 4, and the effect does not penetratc to the blade surface. On the pressure side, however, the wake sweeps the blade surface normally as indicated by the high entropy region near the pressure surface in Figure 5. This allows the wake disturbance to penetrate the boundary layer and impact the coolant flow properties. Figure 13 shows span-average disturbance velocity vectors near the pressure surface for the same time as Figure 5. The disturbance velocity is defined as the instantaneous velocity minus the final steady velocity. This definition allows direct observation of the unsteady effect relative to steady prediction. It can be seen that the disturbance velocity is away from the blade in the wake due to the velocity defect in the wake. This bchavior extends into the coolant flow layer adjacent to the blade. The periodic sweeping of the pressure surface by the wake thus results in a periodic relative lifting of the coolant flow on the pressure surface which likely contributes to the time-average reduction in film effectiveness seen in Figure 9. The increased temperatures predicted in the showerhead region by the unsteady solution can be explained by the effect of the unsteady wake passing. The wake does not allow the film to establish a steady pattern in this region, and the resultant increase in mixing causes hot fluid to be introduced to the surface more effectively.

\section{CONCLUSIONS AND FUTURE WORK}

There are essentially two cffects of wake passing on film cooling: changes in the coolant flow characteristics at the hole exit and changes in the coolant boundary layer. These two effects have been separated by matching the time-average hole exit properties through judicious selection of freestream inlet boundary conditions, leaving only the effect of unsteadiness on the boundary layer. It was determined through the analysis of this report that if the correct coolant flow rate and flow split can be matched, the presence of unsteady wakes has a small effect on the heat transfer bchavior of showerhead film cooling for a representative turbine geometry. The span-average adiabatic film effectiveness is reduced by 2 to 3 percent in the showerhead region and on the pressure surface compared to the steady prediction. Local reductions of up to 8 percent are found in the showerhead region. These reductions are likely due to the periodic relative lifting of the coolant boundary layer from the pressure surface as the wake passes, and enhanced mixing in the showerhead region.
Although the computation was performed for only one film cooling geometry, it was noted that film hole placement and angle is of great importance in achieving a smooth, spanwise uniform coolant film. For the staggered film hole arrangement of this report, the coolant jets tend to "line up" and merge together, leaving portions of the blade practically uncooled. This is especially important in the showerhead region, since this region is exposed to the highest temperatures. The designer should consider these three-dimensional effects to avoid local hot spots, perhaps employing an aligned or less structured film hole pattern in the showerhead region. This will depend on the hole spacing and angle as well, but is true for both steady and unsteady environments.

Many effects related to unsteady coolant flow interactions remain to be explained. As expressed in [13], modeling of the interaction between the turbulent wake and the blade boundary layer has not included the process of turbulent energy entrainment by the boundary layer, and the interaction of freestream turbulence with the boundary layer. An adequate understanding of the film coolant flow structure has yet to be obtained under a variety of test conditions. An upcoming experiment on which the analyses of this report were based may help corroborate these results, and lead to physical models which can be used to predict the effect of unsteady wake passing on turbine film cooling. These models can be used in steady design codes, leading to a more effective use of film coolant in turbine blades. This research program is an example of how computation and experiment can be used effectively in mutual support. The computation guides the design of the expcriment and offers comprehensive prediction, while the experiment lends credibility and accurate focused data.

\section{BEEERENCES}

[1] Sharma, O. P., et al, "Assessment of Unsteady Flows in Turbines", ASME Paper 90-GT-150, June 1990.

[2] Mayle, R. E., "The Role of Laminar-Turbulent Transition in Gas Turbine Engines", Journal of Turbomachinery, Vol. 113, pp. 509-537, Oct. 1991.

[3] Dring, R. P., et al, "An Experimental Investigation of Film Cooling on a Turbine Rotor Blade", Journal of Engineering for Power, Vol. 102, pp. 81-87, Jan. 1980.

[4] Eckert, E. R. G., et al, "Studies of Gas Turbine Heat Transfer: Airfoil Surfaces and End-Wall Cooling Eflccts", Air Force Office of Scientific Research, 
Report N92-19097, ScpL 1991.

[5] Dorney, D. J., et al, "Investigation of Hot Streak Migration and Film Cooling Effects on Heat Transfer in Rotor/Stator Interacting Flows", N00140-88-C-0677 - Report 1, UTRC Report 91-29, Apr. 1992.

[6] Mick, W. J. and Mayle, R. E., "Stagnation Film Cooling and Heat Transfer, Including Its Effect Within the Hole Pattern", Journal of Turbomachinery, Vol. 110, pp.66-72, Jan. 1988.

[7] Ashworth, D. A., et al, "Unsteady Acrodynamic and Heat Transfer Processes in a Transonic Turbine Stage", Joumal of Engineering for Gas Turbines and Power, Vol. 107, pp. 1022-1030, Oct. 1985.

[8] Henderson, G. H., "Forcing Function and Stcady Loading Effects on Unsteady Acrodynamic Gust Response", Ph. D. Thesis, Purdue University, Aug. 1991.

[9] O' Brien, J. E. and Capp, S. P., "Two-Component Phase-Averaged Turbulence Statistics Downstream of a Rotating Spoked-Wheel Wake Generator", Joumal of Turbomachinery, Vol. 111, pp. 475-482, Oct. 1989.

[10] O' Brien, J. E., "Effects of Wake Passing on Stagnation Region Heat Transfer", Journal of Turbomachincry, Vol. 112, pp. 522-530, July 1990.

[11] Abhari, R. S. and Epstein, A. H., "An Experimental Study of Film Cooling in a Rotating Transonic Turbine", ASME Paper 92-GT-201, June 1992.

[12] Chima, R. V. and Yokota, J. W., "Numerical Analysis of Three-Dimensional Viscous Flows in Turbomachinery", AIAA J., Vol. 28, No. 5, pp. 798-806, May 1990.

[13] Abhari, R. S., "An Experimental Study of the Unsteady Heat Transfer Process in a Film Cooled Fully Scaled Transonic Turbine Stage", Ph. D. Thesis, Massachusetts Institute of Technology, Jan. 1991. 

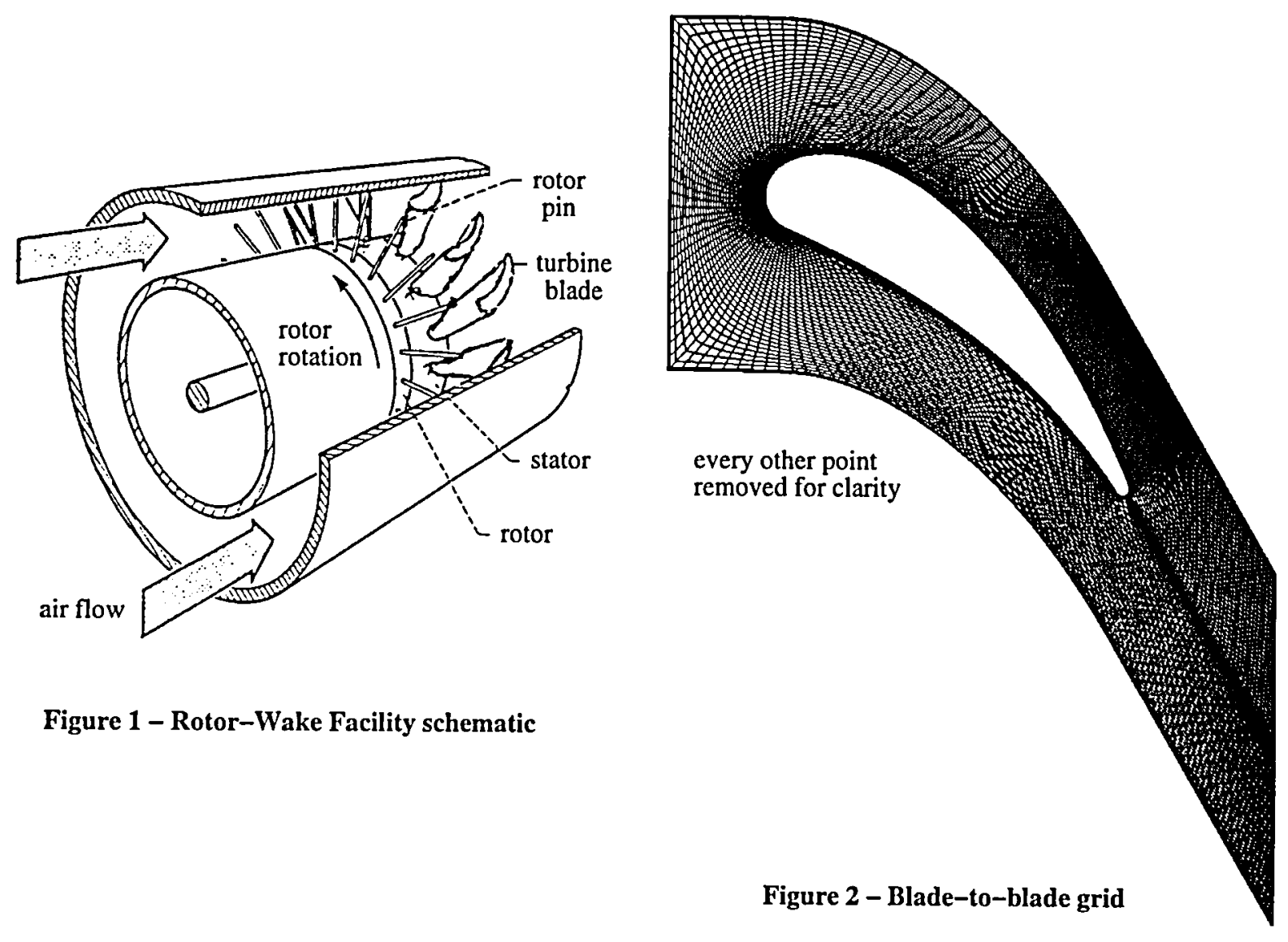

Figure 1 - Rotor-Wake Facility schematic

Figure 2 - Blade-to-blade grid

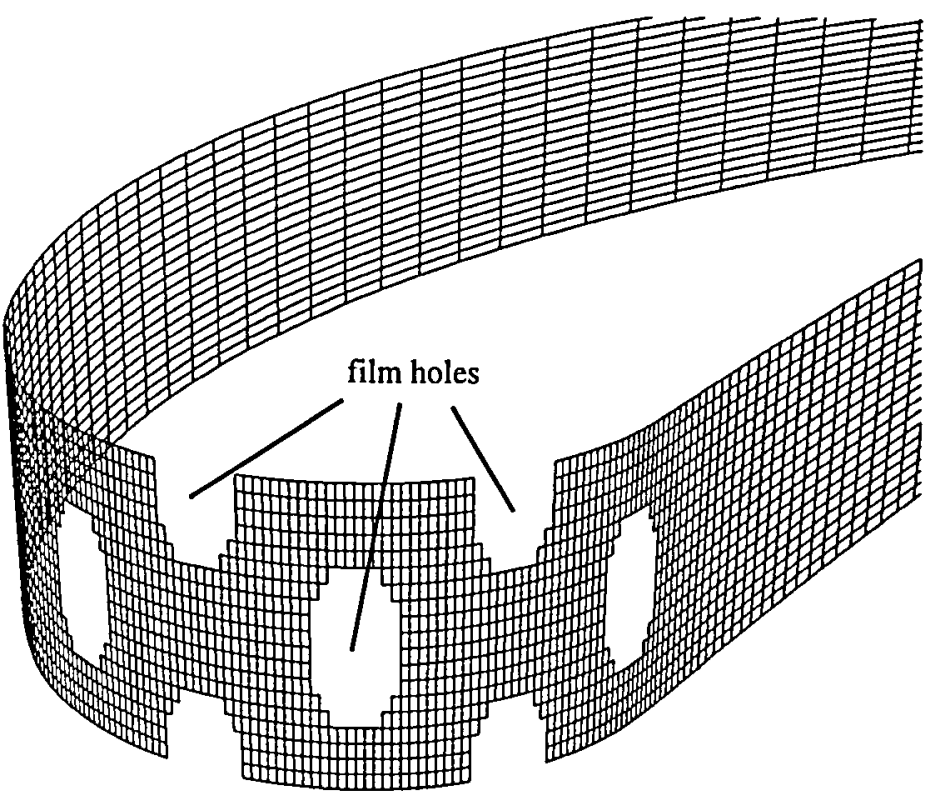

Figure 3 - Blade surface grid 


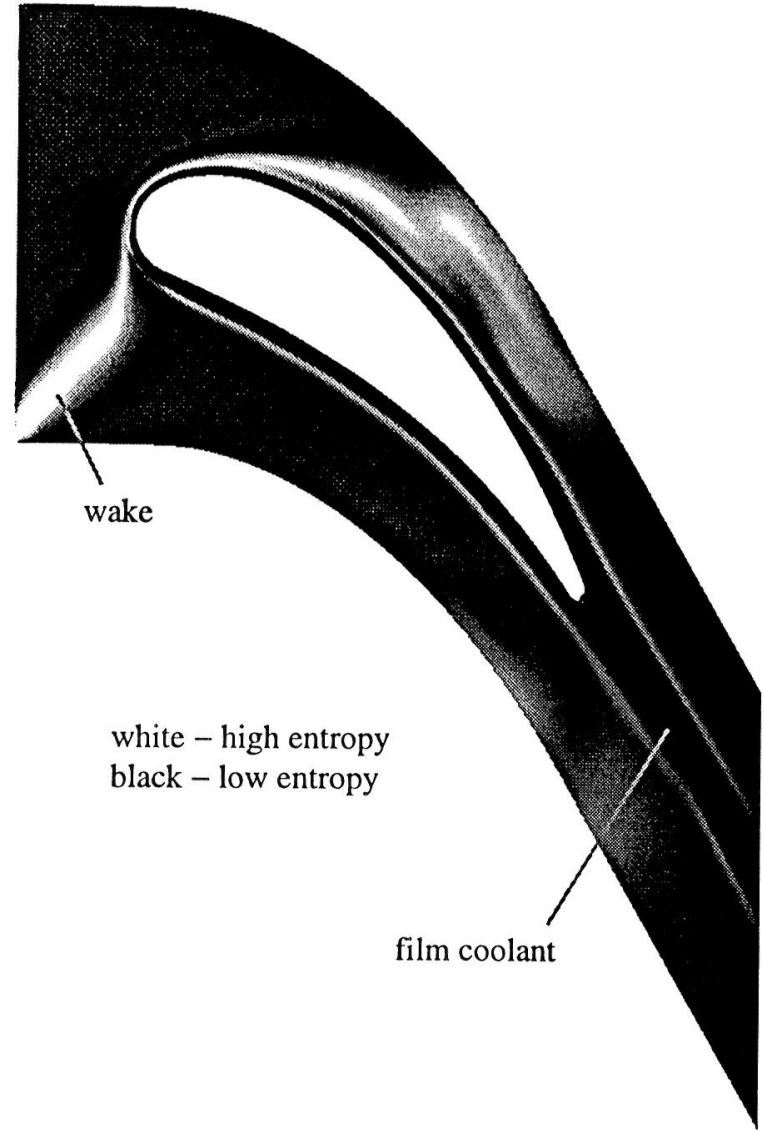

Figure 4 - Span-average entropy for phase $=0^{\circ}$

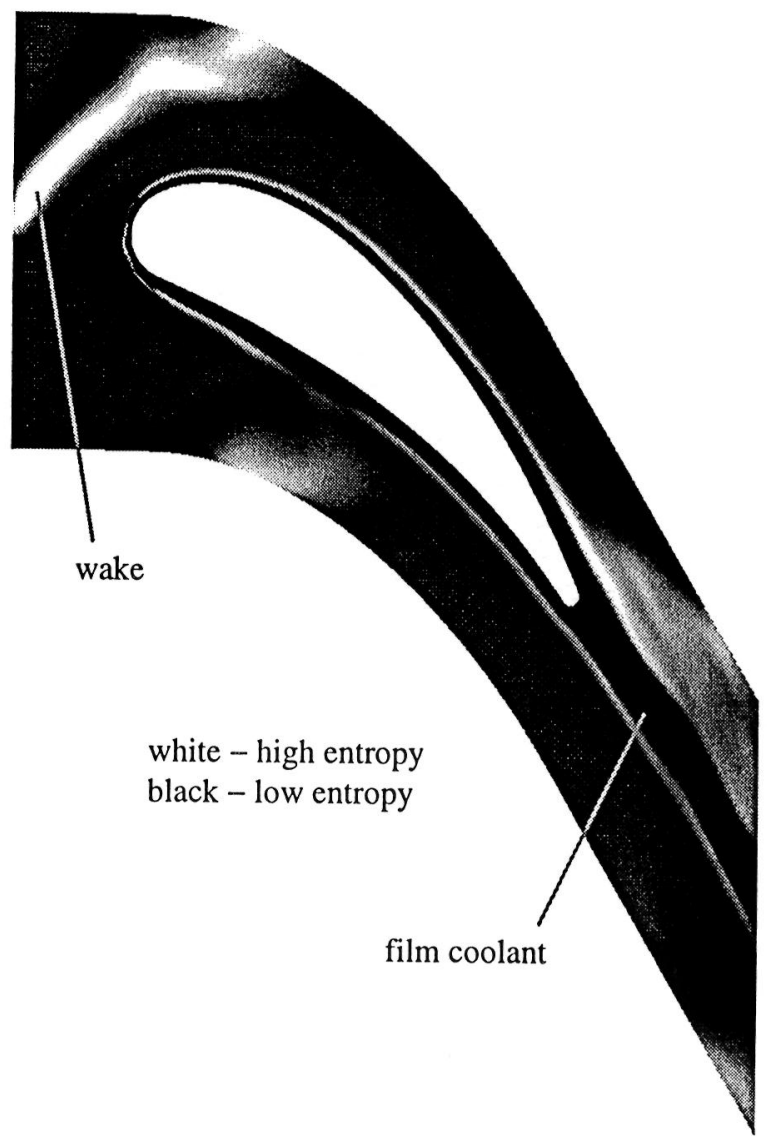

Figure 5 - Span-average entropy for phase $=180^{\circ}$

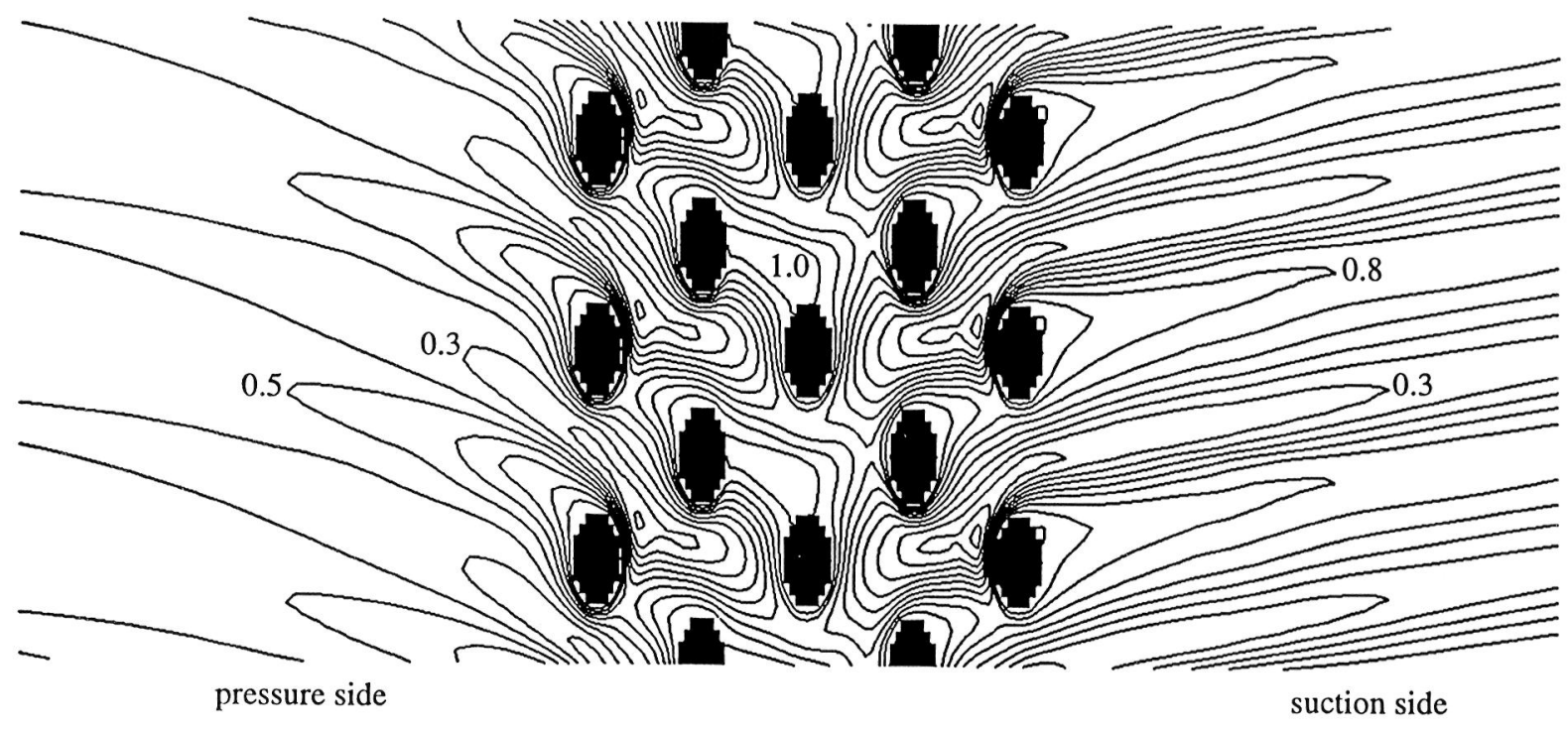

Figure 6 - Time-average unsteady film effectiveness in showerhead region 


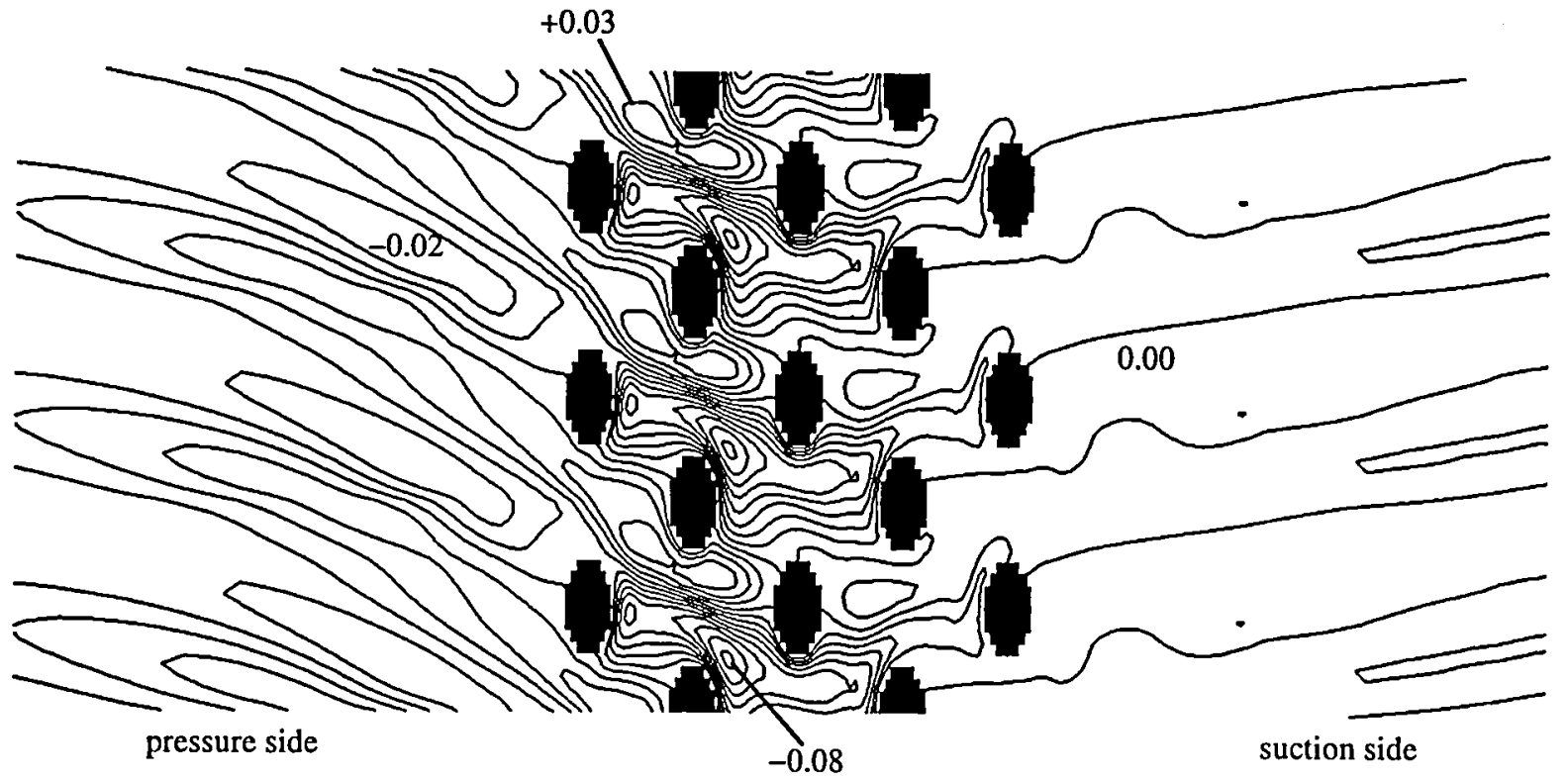

Figure 7 - Time-average unsteady minus final steady film effectiveness in showerhead region

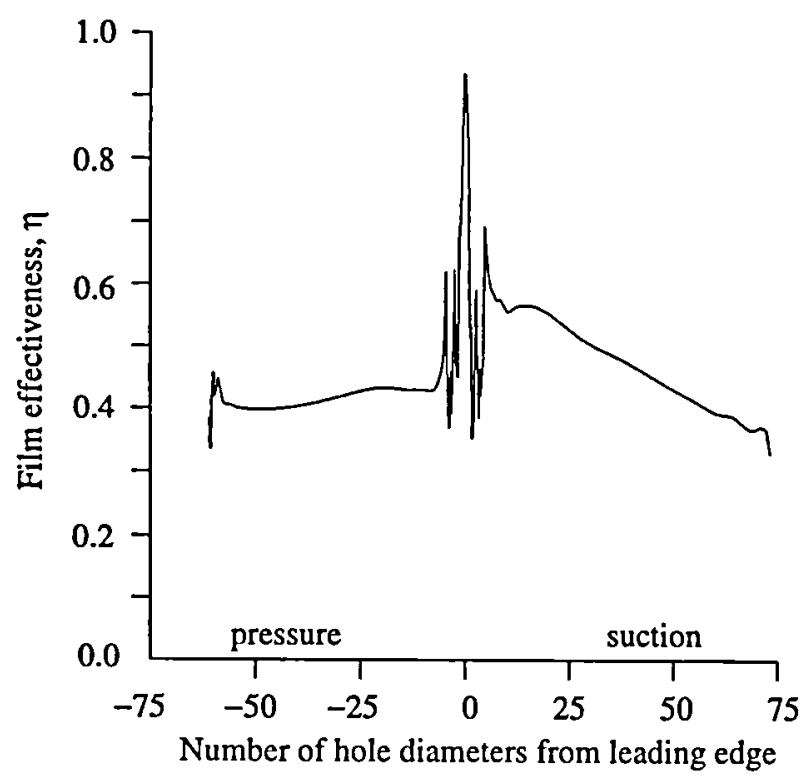

Figure 8 - Span- and time-average unsteady film effectiveness

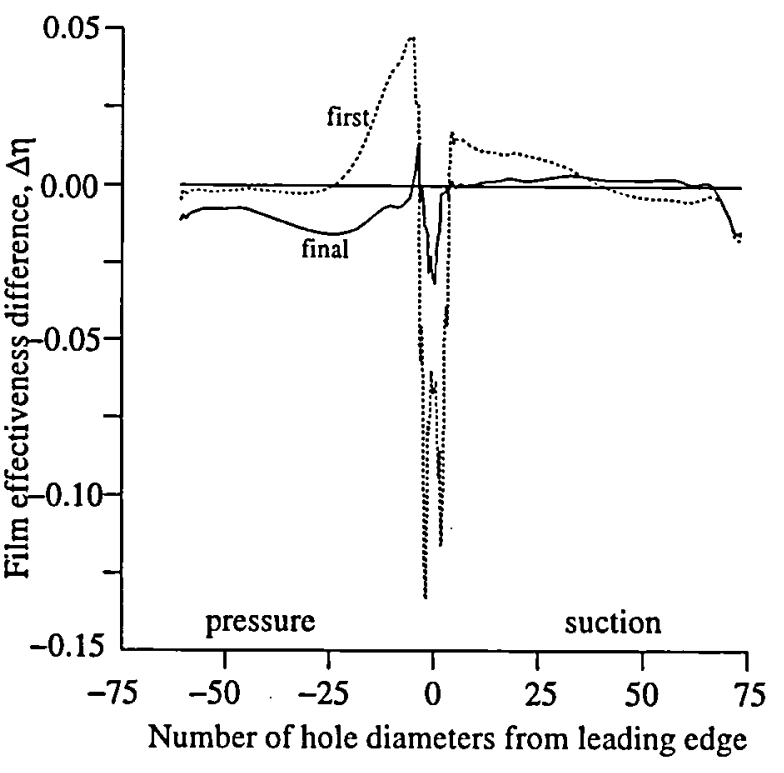

Figure 9 - Span- and time-average unsteady minus span-average steady film effectiveness 


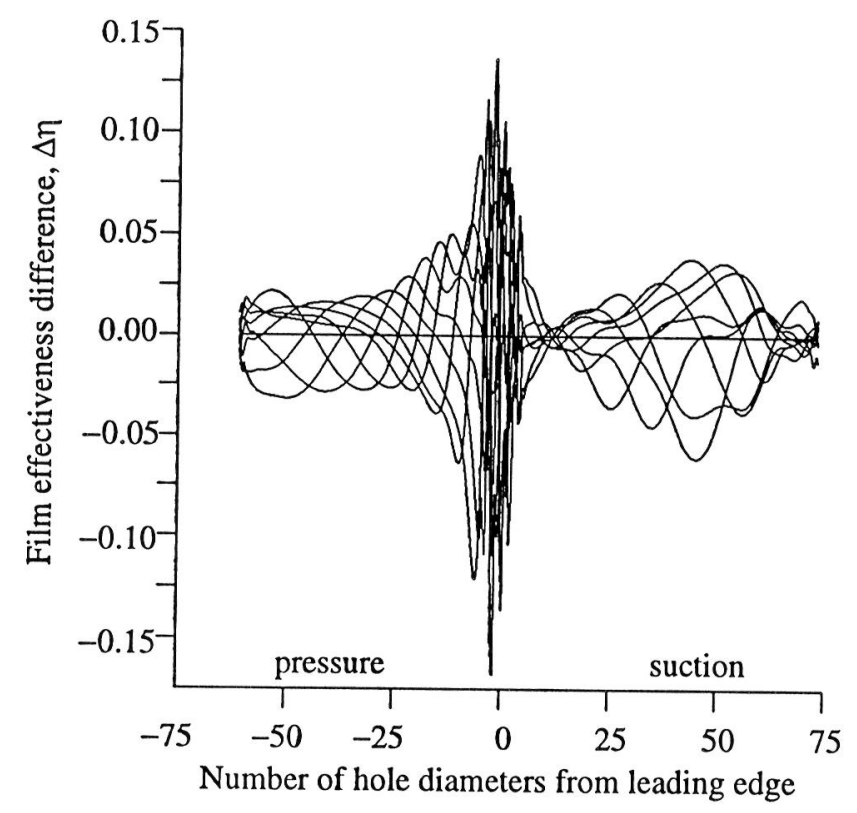

Figure 10 - Span-average instantaneous minus span- and time-average unsteady film effectiveness

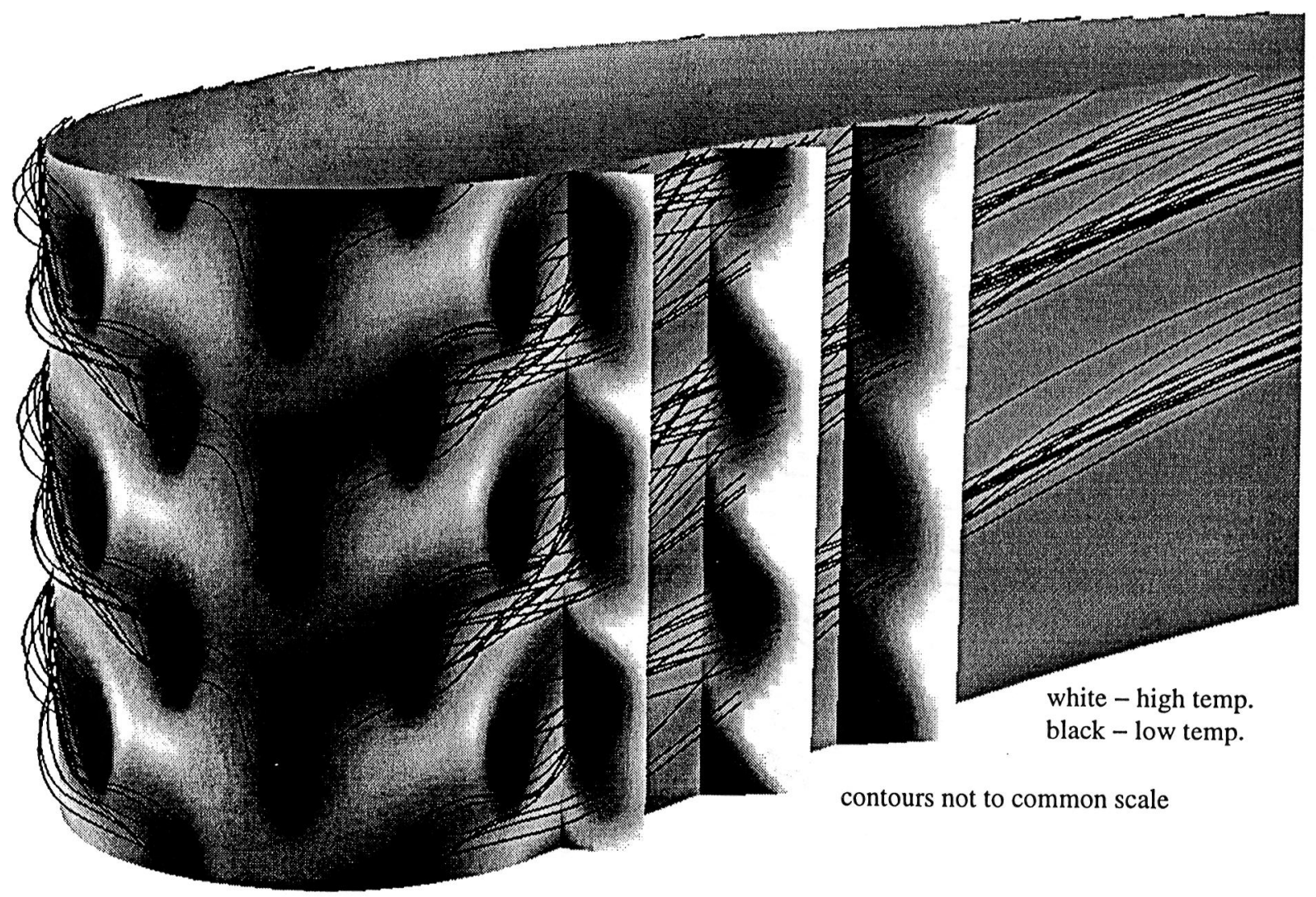

Figure 11 - Wall and cross-plane stagnation temperature contours with time-average particle traces 


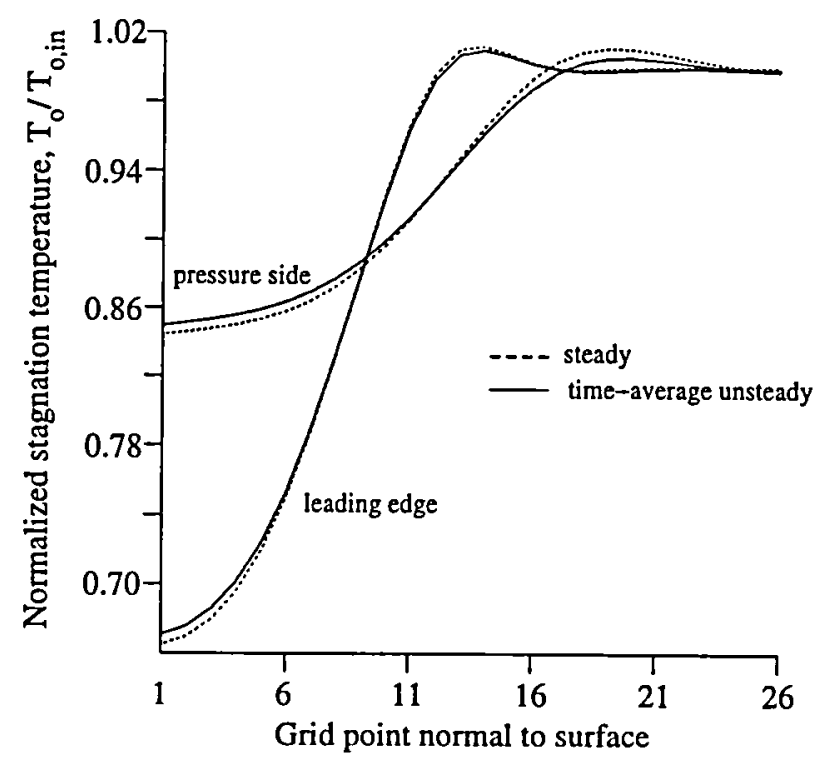

Figure 12 - Cross-plane stagnation temperature plots at two locations

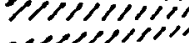

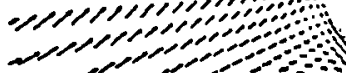
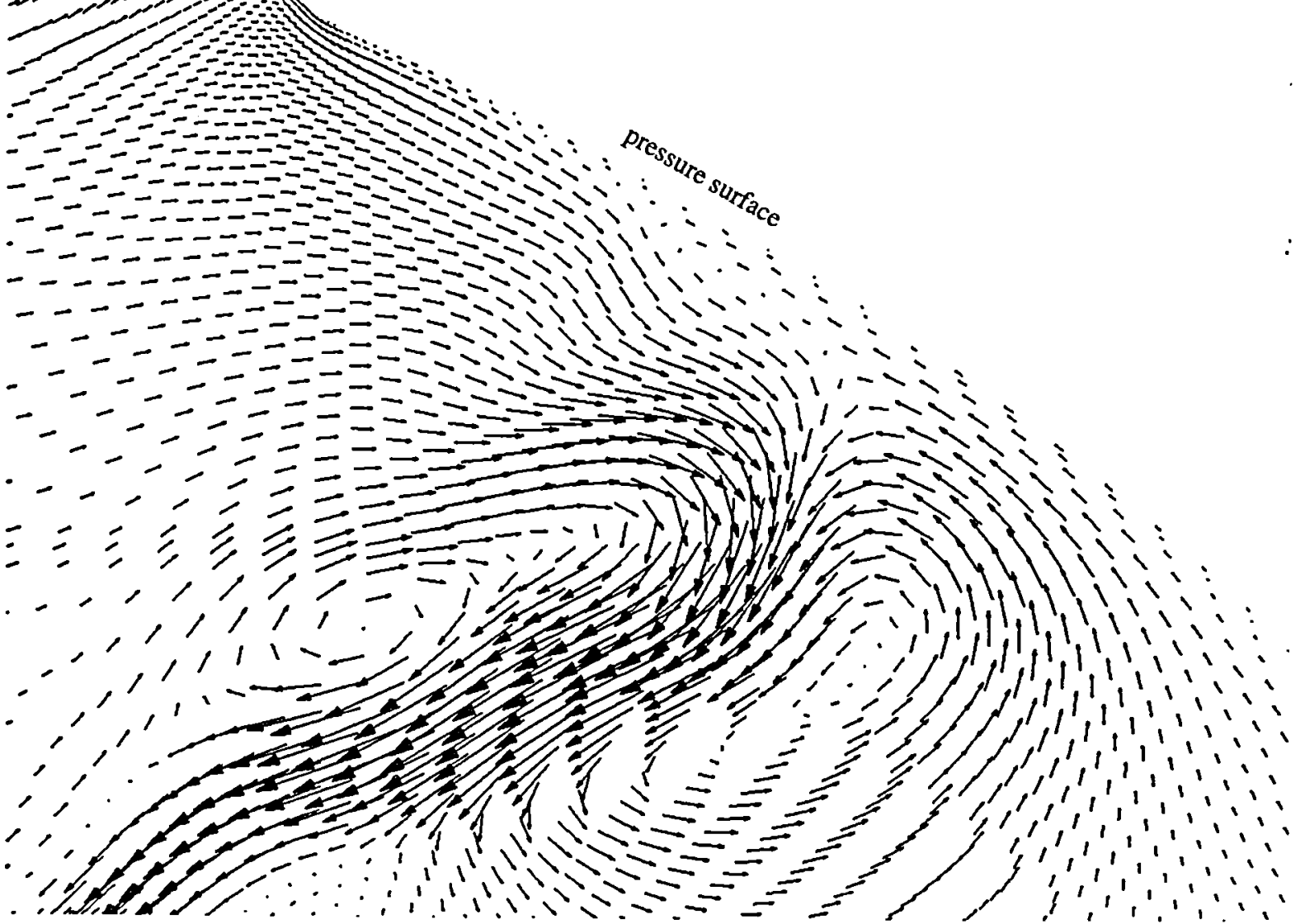

Figure 13 - Instantaneous disturbance velocity at phase $=180^{\circ}$ 
Public reporting burden for this collection of intormation is estimated to average 1 hour per response, including the time for reviewing instructions, searching existing data sources. gathering and maintaining the data needed, and completing and reviewing the colloction of Information. Send comments regarding this burden estimate or any other aspect of this Davis Highway, Suite 1204. Arlington, VA 22202-4302, and to the Ottice of Management and Buds

\begin{tabular}{|l|l|l}
\hline 1. AGENCY USE ONLY (Leave blank) & $\begin{array}{r}\text { 2. REPORT DATE } \\
\text { October } 1995\end{array}$ & $\begin{array}{r}\text { 3. REPORT TYPE AND DATES COVERED } \\
\text { Technical Memorandum }\end{array}$ \\
\hline
\end{tabular}

4. TITLE AND SUBTITLE

October 1995

5. FUNDING NUMBERS

A Numerical Study of the Effect of Wake Passing on Turbine Blade Film Cooling

6. AUTHOR(S)

WU-505-62-10

James D. Heidmann

7. PERFORMING ORGANIZATION NAME(S) AND ADDRESS(ES)

National Aeronautics and Space Administration

Lewis Research Center

Cleveland, Ohio 44135-3191

8. PERFORMING ORGANIZATION REPORT NUMBER

E-9949

9. SPONSORING/MONITORING AGENCY NAME(S) AND ADDRESS(ES)

National Acronautics and Space Administration

Washington, D.C. 20546-0001

10. SPONSORING/MONITORING AGENCY REPORT NUMBER

NASA TM-107077

AIAA-95-3044

11. SUPPLEMENTARY NOTES

Prepared for the 31st Joint Propulsion Conference and Exhibit cosponsored by AIAA, ASME, SAE, and ASEE, San Diego, California, July 10-12, 1995. Responsible person, James D. Heidmann, organization code 2760, (216) 433-3604.

12a. DISTRIBUTIONAVAILABILTY STATEMENT

Unclassified -Unlimited

Subject Category 07

This publication is available from the NASA Center for Acrospace Information, (301) 621-0390.

13. ABSTRACT (Maximum 200 words)

Time-accurate and steady three-dimensional viscous turbulent numerical simulations were performed to study the effect of upstream blade wake passing unsteadiness on the performance of film cooling on a downstream axial turbine blade. The simulations modeled the blade as spanwise periodic and of infinite span. Both aerodynamic and heat transfer quantities were explored. A showerhead film cooling arrangement typical of modern gas turbine engines was employed. Showerhead cooling was studied because of its anticipated strong sensitivity to upstream flow fluctuations. The wake was modeled as a region of zero axial velocity on the upstream computational boundary which translated with each iteration. This model is compatible with a planned companion experiment in which the wakes will be produced by a rotating row of cylindrical rods upstream of an annular turbine cascade. It was determined that a steady solution with appropriate upstream swirl and stagnation pressure predicted the span-average film effectiveness quite well. The major difference is a 2 to 3 percent overprediction of span-average film effectiveness by the steady simulation on the pressure surface and in the showerhead region. Local overpredictions of up to 8 percent were observed in the showerhead region. These differences can be explained by the periodic relative lifting of the boundary layer and enhanced mixing in the undsteady simulations.

\section{SUBJECT TERMS}

Turbines; Heat transfer; Film cooling; Wakes

17. SECURTY CLASSIFICATION OF REPORT Unclassified

18. SECURTY CLASSIFICATION
OF THIS PAGE
Unclassified

19. SECURITY CLASSIFICATION OF ABSTRACT Unclassified

\begin{tabular}{|c|c|}
\hline & $\begin{array}{c}\text { 15. NUMBER OF PAGES } \\
14\end{array}$ \\
\hline & $\begin{array}{r}\text { 16. PRICE CODE } \\
\mathrm{AO} 3\end{array}$ \\
\hline $\begin{array}{l}\text { 19. SECURITY CLASSIFICATION } \\
\text { OF ABSTRACT } \\
\text { Unclassified }\end{array}$ & 20. LIMITATION OF ABSTRACT \\
\hline
\end{tabular}

Standard Form 298 (Rev. 2-89) Prescribed by ANSI Std. Z39-18
298-102 